\title{
O trabalho como operador de saúde
}

\author{
Work as a promoter of health
}

Claudia Osorio da Silva ${ }^{1}$

Tatiana Ramminger ${ }^{1}$

\footnotetext{
${ }^{1}$ Centro de Estudos Gerais, Universidade Federal Fluminense. Campus do Gragoatá Bloco O sala 310, São Domingos. 24210-200 Niterói RJ Brasil. claudiaosorio@terra.com.br
}

\begin{abstract}
Studies on the relation between health and work tend to highlight the negative and pathological aspects, as if work produces only sickness and alienation. On the contrary, our proposal is to stress how work can also produce health. Based on Canguillem's concept of health, and from the contributions of the so-called "work clinics", we intend to analyze the purpose of work as a promoter of health. Canguilhem affirms that health is not adaptive, as such it does not involve adapting well to the world, but to the creation of tenets of life. For their part, the work clinics provide tools to approximate us to the know-howto-do produced by workers in their daily work, namely not only how workers adapt to work, but how they create and recreate it permanently Thus, we can think work as a promoter of health where there is room for collective and personal creation, as well as recognition of workers in their activity. Key words Occupational health, Work, Activity, Work clinics
\end{abstract}

Resumo Os estudos sobre a relação entre saúde e trabalho tendem a destacar seu viés negativo e patológico, como se o trabalho produzisse apenas adoecimento e alienação. Ao contrário, nossa proposta é pensar como o trabalho também pode produzir saúde. A partir do conceito de saúde de Canguilhem e das contribuições das chamadas "clínicas do trabalho", queremos analisar a função do trabalho como operador de saúde. Canguilhem afirma que a saúde não é adaptativa, ou seja, não é um bem adaptar-se ao mundo, mas uma criação de normas de vida. Já as clínicas do trabalho nos fornecem ferramentas para nos aproximar do saber-fazer produzido pelos trabalhadores em seu cotidiano de trabalho, ou seja, de como os trabalhadores não apenas adaptam-se ao trabalho, mas o criam e recriam permanentemente. Sendo assim, podemos pensar no trabalho como operador de saúde quando há lugar para a criação coletiva e pessoal, bem como para o reconhecimento do trabalhador em sua atividade.

Palavras-chave Saúde do trabalhador, Trabalho, Atividade, Clinicas do trabalho 


\section{Introdução}

Marx ${ }^{1}$ já afirmava que modificando a natureza, o homem se modifica e produz a si mesmo. Da mesma forma, Canguilhem ${ }^{2}$ enfatiza que a principal característica do humano não é sua capacidade de adaptar-se ao meio, mas de criar um meio para (melhor) viver. Para ele, o que caracteriza a saúde é justamente a possibilidade de criação e recriação de mundos, a capacidade de instituir novas normas de vida frente às "infidelidades do meio", ou seja, frente a um mundo sempre em transformação. Partindo desta concepção de saúde, a relação entre saúde e trabalho não pode ser pensada somente em seu caráter negativo, como se o trabalho produzisse apenas adoecimento e alienação.

O trabalho seria, então, sempre fonte de desenvolvimento humano? Também não. Segundo uma das linhas teóricas aqui adotadas - a clínica da atividade ${ }^{3}$ - o trabalho só produz saúde quando há atividade. A atividade entra como um conceito chave que iremos explorar ao longo do texto. Por ora, basta afirmar que o impedimento da atividade é a fonte de sofrimento e, frequentemente, de adoecimento.

Temos acompanhado, desde a década de 80 do século XX, o crescimento de uma discussão do trabalho como fonte de sofrimento psíquico e de diferentes quadros associados ao adoecimento mental. O debate que já existia, por exemplo, na França, com Le Guillant, nos anos 1950, retorna, se recompõe e se intensifica.

No Brasil, a criação do campo da Saúde do Trabalhador dá a este debate uma importância específica ${ }^{4-6}$. Este campo insere-se na tradição dos estudos sobre a relação entre saúde e trabalho, diferenciando-se, no entanto, da Medicina do Trabalho ou da Saúde Ocupacional, na medida em que propõe colocar o processo de trabalho (e não o indivíduo) no centro da análise dessa relação, defendendo mudanças em processos de trabalho potencialmente produtores de adoecimento, ao mesmo tempo em que pretende valorizar o saber e a experiência do trabalhador sobre seu próprio trabalho, entendendo-o como sujeito ativo do processo saúde-doença e não, simplesmente, como objeto de atenção à saúde ${ }^{7}$. O peso das estatísticas, somado ao esforço dos pesquisadores e dos movimentos sociais, culminou com o reconhecimento legal da relação entre saúde mental e trabalho no Brasil, apenas em 1999, através do Decreto 3048/99, que discrimina os transtornos mentais relacionados ao trabalho.

No Relatório da Organização Mundial da Saúde, lançado em 1985, são apresentados os re- sultados de estudos realizados sobre transtornos mentais relacionados ao trabalho, estimando-se um índice de 30\% de transtornos mentais menores, e de 5 a $10 \%$ de transtornos mentais graves na população trabalhadora ocupada ${ }^{8}$. Esses índices são confirmados, no Brasil, pelos números da Previdência Social, onde as psiconeuroses ocupam o primeiro lugar entre as causas de incapacidade temporária, e o terceiro lugar entre as de incapacidade permanente e invalidez (Anuário Estatístico da Previdência Social - AEPS, 2011). A partir de 2007, com a adoção do Nexo Técnico Epidemiológico Previdenciário (NTEP), houve um estrondoso aumento de $1157 \%$ no número de benefícios concedidos, considerando a relação entre saúde mental e trabalho, o que evidencia a subnotificação dos agravos, bem como a dificuldade em se estabelecer o nexo causal entre o adoecimento psíquico e a atividade laboral'. Para aqueles não familiarizados com o NTEP, ressaltamos que ele estabelece automaticamente o nexo causal, entre a lesão ou agravo e a atividade desenvolvida pelo trabalhador, considerando o cruzamento das informações do código da Classificação Internacional de Doenças (CID-10) e do código da Classificação Nacional de Atividade Econômica $(\mathrm{CNAE})^{10}$.

Sendo assim, com as mudanças que se observam nos mundos do trabalho e a consequente mudança no perfil de morbimortalidade da população trabalhadora, o sofrimento psíquico, a depressão e as doenças associadas ao estresse (entre elas as cardiovasculares) se tornam mais frequentes e, portanto, objeto de atenção. Nesse quadro, o trabalho aparece na maioria dos estudos como tripalium, como fonte de desgaste e sofrimento, ou como diz Edith Seligmann-Silva ${ }^{11}$, desgaste que ocorre numa situação de trabalho dominado. Especialmente na área da saúde foi realizada em 2012, por Brito et al. ${ }^{12}$, uma extensa revisão de bibliografia referente às pesquisas existentes, onde se verifica que as relações entre condições de trabalho e sofrimento e desgaste são majoritárias em relação àquelas que tratam da saúde na acepção que aqui adotamos.

Essa discussão, sem dúvida necessária, sobre as condições de trabalho precárias e inadequadas e seus possíveis efeitos sobre a saúde dos trabalhadores acaba, muitas vezes, encobrindo a importante função do trabalho como operador de saúde para o ser humano. Buscando melhor desenvolver esse argumento, primeiro apresentamos patrimônios comuns às clínicas do trabalho, quais sejam, a ergonomia, a psicoterapia institucional e a psicopatologia do trabalho. Clínicas do trabalho é uma designação que tenta agrupar di- 
versas vertentes teóricas que desenvolveram-se a partir da psicopatologia do trabalho e da ergonomia francófona, quais sejam, a Psicodinâmica do Trabalho, a Psicossociologia, a Ergologia, a Clínica da Atividade, entre outras. Como percebemos, elas não constituem uma escola de pensamento, nem são homogêneas, mas compartilham pontos em comum, tais como: interesse pela ação dos coletivos de trabalhadores, o entendimento do trabalho como atividade e do trabalhador como sujeito complexo que não se limita ao seu comportamento, a preocupação com a emergência do sofrimento no trabalho e ainda a compreensão da dimensão constitutiva e positiva do trabalho ${ }^{13-15}$.

Em seguida, discorremos sobre as contribuições de duas abordagens das clínicas do trabalho para este tema: a psicodinâmica do trabalho e a clínica da atividade, considerando suas afinidades e discordâncias teóricas, bem como o diálogo com o filósofo George Canguilhem.

\section{Patrimônio partilhado: contribuições da ergonomia, psicoterapia institucional e psicopatologia do trabalho para as clínicas do trabalho}

Ergonomia, no imediato pós-segunda guerra, na Inglaterra, foi a denominação da primeira associação (Ergonomic Research Society) que reunia profissionais de diversas disciplinas, sobretudo a Psicologia, a Fisiologia e as Engenharias, para um empreendimento inovador: adaptar o trabalho ao homem e não o inverso, como operava a Psicotécnica. "Filha da guerra", esta primeira Ergonomia, como tantas outras inovações produzidas a partir desse trágico acontecimento histórico, foi transportada para o mundo industrial, no qual percebiam-se problemas de natureza similar ${ }^{16}$.

A análise ergonômica, como nos explicam Leplat e $\mathrm{Hoc}^{17}$ e Montmollin ${ }^{18}$, tem duas grandes abordagens: uma, identificada com as experiências estadunidenses e britânicas, centrada no componente humano (human factors) do sistema homem-máquina; e outra, que se desenvolveu a partir dos países francófonos, privilegiando a análise da atividade situada, expressão da interação dinâmica entre sujeito e tarefa. O objetivo da primeira abordagem é adaptar os dispositivos tecnológicos às características e limites dos seres humanos e, para tanto, prioriza métodos científicos baseados na generalização e quantificação. Já a segunda, traz como uma das principais contribuições a diferenciação entre trabalho prescrito e trabalho real, avançando posteriormente para os conceitos de tarefa e atividade.
Assim, foi a ergonomia francófona que cunhou o termo "atividade", para diferenciar o trabalho efetivamente realizado da prescrição de uma tarefa ${ }^{13}$. O trabalho prescrito é definido como um conjunto de condições e exigências a partir das quais o trabalho deverá ser realizado, ou seja, incluindo tanto as condições dadas para a realização de um trabalho (ambiente físico, matéria-prima, condições socioeconômicas), como as prescrições propriamente ditas (normas, ordens, resultados exigidos). A ergonomia esforça-se em demonstrar que este trabalho prescrito jamais corresponde ao trabalho real, pois ao realizar uma tarefa, o trabalhador se depara com diversas fontes de variabilidade, desde as mais técnicas até as mais subjetivas. Entre o trabalhador e a tarefa temos, portanto, um terceiro elemento: a atividade de trabalho, que consiste justamente na realização (sempre singular) de um trabalho, considerando-se tanto o trabalho prescrito, como as variabilidades que têm que ser geridas pelo trabalhador.

Para Montmollin ${ }^{18}$ seria mais preciso falar em Ergonomias, complementares, mas não sem contradições. A ergonomia dos componentes humanos seria uma "ergonomia de primeiros socorros" que considera as características dos postos de trabalho (iluminação, calor, umidade, ruídos, assentos, etc.), independente daqueles que os ocupam. Já a ergonomia da atividade permite ao trabalhador interessar-se por sua atividade real, temporal, complexa, rara, aparentemente inventiva e às vezes imperfeita ${ }^{19}$. Ao demonstrar que a situação real de trabalho jamais é apenas o cumprimento de regras pré-estabelecidas, conforme acreditava a gerência racionalizadora taylorista, por exemplo, essa Ergonomia apontou que em qualquer atividade, mesmo aquela considerada mais simples, mecânica ou manual, sempre há uma operação inteligente e uma intensa atividade mental. As estratégias desenvolvidas para gerir a distância entre a tarefa prescrita e a atividade, constituem o chamado "ponto de vista da atividade". Um ponto de vista dentre outros - como o ponto de vista dos resultados, das condições de produção, etc. mas que, em regra, encontra-se excluído ou inteiramente subordinado aos demais.

Também a partir da vivência da guerra, a experiência de alguns psiquiatras franceses foi um marco na discussão sobre a relação entre saúde e trabalho. Nesse período, o risco eminente de bombardeios fez com que alguns hospitais psiquiátricos decidissem libertar os pacientes, mesmo aqueles que supostamente não estariam aptos ao convívio social. Qual não foi a surpre- 
sa quando, ao final da guerra, ao buscarem estes pacientes, os encontraram vivendo seja com suas famílias, seja trabalhando em fazendas ou pequenos negócios, sem problemas que justificassem propostas de reinternação. Para além das propostas adaptativas, o trabalho, com sua chamada à atividade, apresentava-se como fator de desenvolvimento e operador de saúde para todos, mesmo para aqueles com graves transtornos mentais. Essa experiência foi vivida por Tosquelles (Saint Alban), Le Guillant (Villejuif) e muitos outros, marcando o nascimento da psicoterapia institucional e da reforma psiquiátrica francesa.

A partir dessa experiência, Tosquelles desenvolveu a ergoterapia, em um entendimento de que o trabalho pode ser uma terapia, ou seja, pode auxiliar no restabelecimento da saúde. No entanto, como nos chama atenção Clot, Tosquelles tem uma definição bastante peculiar para a ergoterapia. Segundo ele, citado por $\mathrm{Clot}^{20}$ :

Não se trata de fazer os doentes trabalharem para diminuir tal ou qual sintoma. Trata-se de fazer trabalhar os doentes e o pessoal que os cuida, para cuidar da instituição. Para que a instituição e o pessoal de saúde captem no vivo que os doentes são seres humanos sempre responsáveis por aquilo que fazem, o que só pode ser colocado em evidência na condição de fazer alguma coisa.

Cuidar, como ressalta Clot, tem um duplo sentido: transformar o trabalho e fazer um trabalho bem feito. Aqui já temos uma pista de como o trabalho pode ser operador de saúde, a partir da condição dos trabalhadores transformarem sua situação de trabalho e se reconhecerem no trabalho bem realizado.

O que ocorreu durante a guerra, na análise de Tosquelles, foi a chamada dos doentes à atividade, para cuja definição ele chama atenção: atividade, na noção adotada por ele, seguindo Simon, não tem nada a ver com agitação, andar de um lado para o outro, ou qualquer outro movimento feito por imposição alheia. A noção adotada remete à "atividade própria: pessoal e personalizante, aquela que toma como fonte e se enraíza em cada um"21. No mesmo texto, Tosquelles afirma que está aí, na chamada à atividade, a justificativa do sucesso das comunidades terapêuticas. O cuidar da instituição refere-se, assim, a não ser complacente com nenhum dos envolvidos, convocando-os todos à atividade, principalmente os doentes, já que é considerada em seu potencial de produtora de saúde.

Já para outros psiquiatras, como Le Guillant e Sivadon, os efeitos das experiências pós-guerra levaram a outros estudos, que apontaram para a estreita relação entre determinadas ocupações e o adoecimento psíquico, dando origem aos estudos sobre Psicopatologia do Trabalho ${ }^{22}$. Junto com a Ergonomia, a Psicopatologia do Trabalho formou a base inicial mais influente da tradição da clínica do trabalho francesa, concentrando sua atenção nos modos de adoecimento psíquico relacionados ao trabalho, em um entendimento de que a organização do trabalho capitalista era nociva à saúde mental dos trabalhadores ${ }^{23,24}$. $\mathrm{O}$ projeto mais influente, representado por Le Guillant, era o de chegar a um mapeamento das formas de adoecimento ligadas ao trabalho. Seus referenciais teóricos e metodológicos foram se diferenciando da abordagem do condicionamento clássico pavloviano à fenomenologia e mesmo à gestalt ${ }^{23,25}$.

Ressaltamos que esses autores e abordagens serão apropriados de diferentes maneiras nas discussões das décadas seguintes, acerca das relações entre trabalho e saúde.

\section{A normalidade como enigma}

Já no final dos anos 1970, a segunda geração da psicopatologia do trabalho, liderada por Dejours, observou que os trabalhadores não se revelavam passivos frente aos constrangimentos organizacionais, desenvolvendo sistemas defensivos coletivos (estratégicos e ideológicos) para se proteger desses constrangimentos e dos riscos de adoecerem. O foco, portanto, deixa de ser a busca de detecção das doenças mentais ocasionadas pelo trabalho e passa a ser o sofrimento e as defesas contra o sofrimento no trabalho, ou ainda, a normalidade e não a doença mental ${ }^{11,25}$. Aos poucos, Dejours inverte a pergunta-chave da psicopatologia do trabalho, questionando-se não mais sobre como o trabalho "enlouquece" os trabalhadores, mas sobre como os trabalhadores, mesmo quando sujeitos às mais diversas pressões patogênicas no trabalho, conseguem evitar a doença mental e a loucura. É a normalidade, portanto, que emerge como enigma na relação entre saúde e trabalho.

Como o próprio autor explica:

Simultaneamente, era a 'normalidade' que surgia como enigma central da investigação e da análise. Normalidade que ocorre, de saída, como equilíbrio instável, fundamentalmente precário, entre o sofrimento e as defesas contra o sofrimento [...]. Ao operar esta passagem da patologia à normalidade, sou levado a propor uma nova nomenclatura para designar essas pesquisas: Psicodinâmica do Trabalho ${ }^{25}$. 
Dejours salienta que o desenvolvimento de seus estudos foi possível graças a um duplo diálogo: com a psicanálise e com a ergonomia (além da fenomenologia social, da sociologia compreensiva, da ética, do trabalho e das relações de gênero). A partir da diferença apontada pela ergonomia, entre trabalho prescrito e trabalho real, Dejours interessou-se pelos processos organizativos e subjetivos que colaboram para a luta pela saúde, propondo a definição de trabalho como "a atividade manifestada por homens e mulheres para realizar o que ainda não está prescrito pela organização do trabalho"25.

Dar conta daquilo que não está prescrito, exige inventividade, criatividade e formas de inteligência específicas, as quais Dejours denomina "engenhosidade" ou "inteligência da prática, do corpo". Toda atividade de trabalho inclui, segundo o autor, uma forte mobilização subjetiva que, por um lado é "espontânea", mas por outro, não deixa de ser extremamente frágil, dependendo da dinâmica existente entre contribuição e retribuição, envolvendo o julgamento de outrem. O trabalhador espera reconhecimento simbólico da sua contribuição, sem o qual tende a desmobilizar-se, com profundas consequências para sua saúde mental:

Assim, a psicodinâmica do trabalho completa a análise dinâmica do sofrimento e das estratégias defensivas mediante a análise dinâmica do sofrimento e sua transformação em prazer pelo reconhecimento. $O$ trabalho oferece amálgama ao conjunto 'sofrimento e reconhecimento'. Se falta reconhecimento, os indivíduos engajam-se em estratégias defensivas para evitar a doença mental, com sérias consequências para a organização do trabalho, que corre o risco de paralisia ${ }^{25}$.

Vejamos, em seguida, como a clínica da atividade converge e se diferencia da psicodinâmica do trabalho, considerando o papel do trabalho como operador de saúde.

Trabalhar, 'sair de si': a função psicológica do trabalho

O trabalho, para a clínica da atividade, exerce na vida pessoal uma função psicológica específica. E isso porque o trabalho é uma atividade dirigida ${ }^{3}$. A atividade é dirigida a outrem - aos pares, aos chefes -, é também dirigida ao objeto de trabalho; e dirigida ao que Bakhtin ${ }^{26}$ chama de sobre destinatário. Um destinatário 'de segurança' que, no caso da atividade de trabalho, é o ofício. Em especial, a dimensão transpessoal do ofício, a dimensão do gênero de atividade profissional.
O ofício, em uma definição psicológica do termo, é ao mesmo tempo pessoal, interpessoal, impessoal e transpessoal. Ele é, estruturalmente, o movimento resultante do conflito entre essas quatro dimensões que o constituem. A dimensão impessoal está relacionada às tarefas prescritas das organizações e instituições, mas para que o ofício se desenvolva, é preciso que também esteja vivo em suas outras dimensões: "ele vive também - ou morre - entre profissionais e em cada um deles na motricidade dos diálogos em que se realizam, ou não, as trocas intrapessoais e interpessoais sobre o real do trabalho. Os profissionais envolvidos na atividade são diretamente responsáveis por essa vida. Trata-se do trabalho coletivo para realizar a tarefa e repensá-la coletivamente na atividade conjunta"27.

A atividade produz e mantém a quarta dimensão de existência do ofício, a dimensão transpessoal: a história e a memória profissional que se configuram como um meio de agir no presente e de dimensionar o futuro. "Essa memória é aqui designada como transpessoal, visto que não pertence a ninguém, é um meio disponível para todos e para cada um, atravessa gerações e, inclusive, cada profissional"27. A dimensão transpessoal corresponde ao que, em clínica da atividade, se define como o gênero da atividade profissional $^{3,27}$.

O trabalho é, então, a capacidade de estabelecer engajamentos em uma história coletiva. Trabalhar é sair de si, inscrever-se em "uma história coletiva cristalizada em gêneros sociais em geral suficientemente equívocos e discordantes para que possam transformar-se a partir das novas experiências vivenciadas pelos trabalhadores, para que cada um deva 'dar sua própria contribuição' e sair de si”’3.

Clot toma como ponto de partida a mesma definição de coletivo forjada por D. Cru. Para esse autor, nem todo "trabalho coletivo implica um coletivo de trabalho", uma vez que este último exige "simultaneamente, vários trabalhadores, uma obra e linguagem comuns, determinadas regras de ofício, além de respeito duradouro dessas regras por cada um, o que impõe uma evolução individual que vai do conhecimento das regras à sua interiorização"27.

No trabalho há sempre muitas variações possíveis. Há uma distância entre o prescrito e o realizado que exige que o sujeito crie soluções, faça escolhas entre vários caminhos possíveis. As variações técnicas, sociais e pessoais exigem o trabalho da subjetividade. Para isso, o trabalhador vale-se tanto da prescrição (um recurso 
de grande importância), como dos recursos de gênero, coletivamente construídos, disponíveis, mas suficientemente insuficientes para obrigar à inventividade ou àquilo que, na clínica da atividade, entende-se como atividade.

De acordo com a clínica da atividade, a subjetividade é produzida na atividade, mas não pode ser vista como mera projeção mecânica desta. A partir de Vygotski, o desenvolvimento do sujeito não é pensado como simples progressão, mas como uma metamorfose. O desenvolvimento do poder de agir pode abrir uma crise nos modos habituais de pensar, viver, trabalhar. A partir de Spinoza, $\mathrm{Clot}^{27}$ afirma que a subjetividade não é uma disposição constitutiva do sujeito, mas refere-se ao poder de ser afetado. "O esforço para desenvolver o poder de agir não está separado de um esforço para elevar, ao grau mais elevado, o poder de ser afetado".

Nesse inacabamento dos recursos de gênero, o sujeito é levado a explorar também recursos de outras fontes, como aqueles de sua própria história, profissional ou mesmo pessoal. E confrontado com a necessidade de fazer escolhas, seguir por um caminho, abandonando outros.

Ao lado de Vygotski ${ }^{28}$, considera-se que o "homem está pleno a cada minuto de possibilidades não realizadas". Tais possibilidades não realizadas constituem um plano em que o sujeito pode agir mais ou menos livremente; em que o sujeito pode, inclusive, resistir quando se tenta amputar seu poder de agir.

O trabalho nos coloca a todo instante frente a impasses. Se os trabalhadores não dispõem de recursos para ultrapassá-los, ou de meios para desenvolver tais recursos, estão em situação de atividade impedida ou contrariada. $\mathrm{O}$ trabalho, portanto, só produz saúde quando há atividade, sendo que a situação de atividade impedida é uma situação de sofrimento e desgaste.

Vamos novamente lembrar Canguilhem²: "Patológico implica pathos, sentimento direto e concreto de sofrimento e impotência, sentimento de vida contrariada". Seguindo esse modo de pensar, compreendemos por que a clínica da atividade afirma que a atividade impedida é fonte de sofrimento e, frequentemente, de adoecimento.

Ainda inspirados em Canguilhem, referência importante para Clot e outros autores, podemos dizer que o trabalho será operador de saúde quando for normativo, ou seja, propiciar a fabricação de normas, ou de constantes, que Canguilhem chamou de normas propulsivas, aquelas que não constituem obstáculo a novas normas. Já as normas de valor repulsivo susten- tam uma vida limitada. Elas não suportam tantas variações, forçando o indivíduo a se preservar de mudanças.

Situações em que o trabalhador é coagido, como na organização do trabalho taylorista, a camuflar sua inventividade, restringem também essa função do trabalho como operador de saúde. Também na situação atual, em que prescrições paradoxais, de produzir perseguindo metas sempre mais altas, com excelência e com o mínimo de recursos, percebe-se o impedimento da atividade normativa dos trabalhadores e um terreno fértil para o adoecimento. Sendo assim, a atividade normativa, na situação de trabalho, se dá no diálogo e no conflito entre as dimensões do ofício. Se, neste diálogo, o trabalhador pode se reconhecer como integrante do coletivo de ofício, a possibilidade de ousar criar está preservada.

$\mathrm{Na}$ clínica da atividade o conceito de reconhecimento toma então um rumo diferente daquele que tem na psicodinâmica do trabalho. $\mathrm{O}$ importante, do ponto de vista da clínica da atividade, é a possibilidade que os trabalhadores têm de se reconhecer no que fazem. E essa possibilidade se dá em função do modo como se inscrevem na história de um ofício, que não pertence a ninguém em particular, mas pela qual todos se sentem responsáveis. A mobilização subjetiva no trabalho está direcionada para um sobre destinatário, a instância transpessoal do ofício.

$\mathrm{Na}$ atividade, o destinatário de segurança é o gênero: a dimensão transpessoal do ofício. $\mathrm{O}$ sujeito deve sempre dialogar com o ofício, questioná-lo, mas sempre respeitando esse patrimônio. O trabalho realizado precisa ser coerente com o que o ofício consagrou, mas acrescentando aí algo mais, pondo algo de si e dando vitalidade a este ofício. A controvérsia, o debate de escolas, renova tanto a instância transpessoal do ofício, $o$ gênero, quanto retorna sobre as prescrições mais estabilizadas, a sua instancia impessoal, modificando-as.

Nas palavras de Yves Clot,

nada é mais importante que 'atacar' o oficio para defendê-lo. Ele só pode durar se a última palavra não for jamais dita, e o último gesto não for jamais completado. Portanto a vitalidade interpessoal do oficio repousa por inteiro sobre os ombros de cada trabalhador, e todos são responsáveis para preservá-lo da imutabilidade ${ }^{29}$.

Sendo assim, é importante, para a manutenção da saúde, que o trabalhador possa, além de realizar suas tarefas, contribuir para a renovação e para a vitalidade daquilo que ele tem em comum com seus pares: seu ofício. $\mathrm{Na}$ enorme 
intensificação do trabalho que observamos atualmente, na precarização do trabalho, no medo do desemprego, nem sempre o trabalhador pode contar ou contribuir com essa tradição coletivamente construída. Trabalho corrido, cansaço, metas inalcançáveis são obstáculos para que o trabalhador possa contribuir para a história de seu ofício.

Vemos hoje então um enfraquecimento da função psicológica do trabalho enquanto operador de desenvolvimento humano, pessoal e coletivamente considerado. A função psicológica do trabalho se expressa no momento em que o homem pode dele destacar-se, quando não se percebe mais como fundido com sua tarefa e, ainda, quando a ação tende a aumentar seu poder de afetar e ser afetado.

É interessante ressaltar que, desse ponto de vista, quanto mais história coletiva, quanto mais recursos de ofício, mais recursos para a singularidade. $\mathrm{Ou}$, como Yves Clot gosta de dizer, quanto mais coletivo, mais sujeito.

\section{Trabalho e saúde: o fio da navalha}

Em ambas as abordagens das clínicas do trabalho, percebemos que a distância entre trabalho prescrito e real, e a produção coletiva de modos de lidar com essa defasagem, dão lugar a pensar o trabalho como operador de saúde. Da mesma forma, destaca-se a função do reconhecimento no trabalho.

Esse tema tem chamado a atenção dos psicólogos no Brasil, inicialmente a partir da leitura da psicodinâmica do trabalho. Como vimos, Dejou$\mathrm{rs}^{25}$ propõe a análise dinâmica do sofrimento no trabalho e sua transformação em prazer pelo reconhecimento. Se falta reconhecimento, os trabalhadores desenvolvem estratégias defensivas para evitar o adoecimento, com graves consequências para a saúde dos trabalhadores e a organização do trabalho.

$\mathrm{Na}$ clínica da atividade, o reconhecimento que produz saúde se dá no reconhecimento do trabalhador, por si mesmo, produzido pela avaliação de que realiza um trabalho bem feito, do qual pode se orgulhar. Os critérios do 'bem feito' são fabricados continuamente na dinâmica do ofício, na permanente construção e reconstrução do gênero de atividade profissional.

Afirmar que o trabalho pode ser operador de saúde não é tentar escamotear a nocividade dos modos de organização de trabalho hegemônicos na atualidade. Ao contrário, se nos aprofundarmos na concepção de saúde de Canguilhem², aqui apresentada, veremos o quanto ela pode nos auxiliar na ampliação do poder de agir dos trabalhadores. Considerando as características predominantes nos modos de trabalhar contemporâneos, percebemos que a potência normativa do trabalhador é prejudicada não por ter que lidar com o erro ou o acaso inerentes à vida, mas principalmente por condições adversas perfeitamente evitáveis. Se, para esse autor, o conceito de saúde se define pela capacidade de tolerância às infidelidades do meio, a partir da criação de normas, ampliar esta capacidade é uma tarefa coletiva, que inclui a transformação das condições sociais.

\section{Colaboradores}

CO Silva e T Ramminger contribuíram na construção do argumento e na redação do texto. 


\section{Referências}

1. Marx K. O Capital: crítica da economia política: livro 1. Rio de Janeiro: Civilização Brasileira; 2011.

2. Canguilhem G. O normal e o patológico. Rio de Janeiro: Forense Universitária; 1990.

3. Clot Y. A função psicológica do trabalho. Petrópolis: Vozes; 2006.

4. Minayo-Gomez C, Thedim-Costa SMF. Incorporação das ciências sociais na produção de conhecimentos sobre trabalho e saúde. Cien Saude Colet 2003; 8(1):125136.

5. Minayo-Gomez C, Lacaz FAC. Saúde do Trabalhador: novas-velhas questões. Cienc Saude Colet 2005; 10(4):797-807.

6. Tambellini, AT, Câmara VM. A temática saúde e ambiente no processo de desenvolvimento do campo da saúde coletiva: aspectos históricos, conceituais e metodológicos. Cien Saude Colet 1998, 3(2):47-59.

7. Minayo-Gomez C, Thedim-Costa SMF. A construção do campo da saúde do trabalhador: percurso e dilemas. Cad Saude Publica 1997; 13(Supl. 2):21-32.

8. World Health Organization (WHO). Expert Committe on Identification and Control of Work Related Diseases. Geneva: WHO; 1985.

9. Seligmann-Silva E, Bernardo, MH, Maeno, M, Kato, M. O mundo contemporâneo do trabalho e a saúde mental do trabalhador. Revista Brasileira de Saúde Ocupacional 2010; 35(122):187-191.

10. Brasil. Ministério da Previdência Social. Anuário Estatístico da Previdência Social de 2011. [acessado 2013 abr 26]. Disponível em: http://www.previdencia.gov.br/ conteudoDinamico.php?id=423\#p1

11. Seligmann-Silva E. Desgaste mental no trabalho dominado. Rio de Janeiro: Editora UFRJ, Editora Cortez; 1994.

12. Brito J, Pena P, Gomes L, Souto A, Pires A. A saúde dos trabalhadores de saúde: focos, abordagens e estratégias de pesquisa. In: Machado J, Assunção A, organizadores. Panorama da saúde dos trabalhadores da saúde. Belo Horizonte: UFMG; 2012. p. 66-105.

13. Bendassoli PF, Soboll LAP. Clínicas do trabalho: filiações, premissas e desafios. Cadernos de Psicologia Social do Trabalho 2011; 14(1):59-72.

14. Ramminger T, Athayde MRC, Brito J. Ampliando o diálogo entre trabalhadores e profissionais de pesquisa: alguns métodos de pesquisa-intervenção para o campo da Saúde do Trabalhador. Cien Saude Colet 2013; 18(11):3191-3202.

15. Brito J. Trabalho e Saúde Coletiva: o ponto de vista da atividade e das relações de gênero. Cien Saude Colet 2005, 10(4):879-890.

16. Teiger C. O trabalho, esse obscuro objeto da Ergonomia. In: Castillo JJ, Villena J, organizadores. Ergonomia: conceitos e métodos. Lisboa: Dinalivros; 2005. p. 47-60.
17. Leplat J, Hoc JM. Tarefa e atividade na análise psicológica de situações de trabalho. In: Castillo JJ, Villena J, organizadores. Ergonomia: conceitos e métodos. Lisboa: Dinalivros; 2005. p. 10-35.

18. Montmollin M. Ergonomias. In: Castillo JJ, Villena J, organizadores. Ergonomia: conceitos e métodos. Lisboa: Dinalivros; 2005. p. 36-46.

19. Wisner A. A inteligência no trabalho. São Paulo: Fundacentro; 1994.

20. Clot Y. A psicologia do trabalho na França e a perspectiva da clínica da atividade. Fractal: Revista de Psicologia 2010; 22(1):207-234.

21. Tosquelles F. Le travail thérapeutique en psychiatrie. Toulouse: Eres; 2009.

22. Lima MEA, organizadora. Escritos de Louis Le Guillant: da ergoterapia à psicopatologia do trabalho. Petrópolis: Vozes; 2006

23. Zambroni-de-Souza PC, Athayde M. A contribuição da abordagem clínica de Louis Le Guillant para o desenvolvimento da Psicologia do Trabalho. Estudos e Pesquisas em Psicologia 2006; 6(1):6-19.

24. Zambroni-de-Souza PC. O pioneirismo de Louis Le Guillant na reforma psiquiátrica e psicoterapia institucional na França: a importância do trabalho dos pacientes para a abertura dos hospícios. Estudos e Pesquisas em Psicologia 2009; 9(3):612-631.

25. Dejours C. Addendum. In: Lancman S, Sznelwar LI, organizadores. Christophe Dejours: da psicopatologia à psicodinâmica do trabalho. Rio de Janeiro: Fiocruz; 2004. p. 47-104.

26. Bakhtin M. Estética da Criação Verbal. São Paulo: Martins Fontes; 2006.

27. Clot Y. Trabalho e poder de agir. Belo Horizonte: Fabrefactum; 2010 .

28. Vygotski L. Conscience, inconscient, émotions. Paris: La Dispute; 2003.

29. Clot Y. Clínica do trabalho e clínica da atividade. In: Bendassoli P, Soboll L, organizadores. Clínicas do trabalho: novas perspectivas para a compreensão do trabalho na atualidade. São Paulo: Atlas; 2011. p. 71-83.

Artigo apresentado em 27/08/2013

Aprovado em 14/01/2014

Versão final apresentada em 19/01/2014 